be, which literally means that each of the two limits is equally valid. Yet much of the British public water supply, especially where nitrate fertilizers are intensively used in agriculture, contravenes the EC limit. The consequence is that water utilities will be required to spend extra on treatment plants in the years ahead, while the government has already agreed to compensate some farmers for not using as much fertilizer as they might otherwise have done. That is another pointless but expensive fuss.

Less than a year has passed since the British prime minister, Mrs Margaret Thatcher, took her electors and political opponents by surprise with her declaration that people should worry about the prospect that the accumulation of infrared absorbing gases in the atmosphere may induce climatic change. On that score, Mrs Thatcher is entirely right. But there is also a strong presumption that she, like politicians elsewhere, is seeking not only to take the lead in warning of a substantial environmental danger, but also to win general support from voters inclined towards environmental causes. Certainly there has been little attempt by the British government (or, for that matter, its counterparts elsewhere) to argue that the potential seriousness of the greenhouse effect may limit the attention it is possible to devote to other environmental nuisances. But that is the reality. It is a simple matter of economics. Even if, in the next few years, it is possible to reach an international understanding to limit the quantities of greenhouse gases reaching the atmosphere, the difficulties will only then have begun. Industrialized countries will find themselves having to behave as if the price of energy were much greater than it needs to be. Developing countries, meanwhile, will be denied the more obvious paths to economic development. That is why it gives such great offence that an alliance of British dockers and environmentalists should have chosen to make a pantomimic empty gesture on behalf of PCBs.

\section{Planck too constant}

West Germany's Max Planck Society wrings its hands about immobility in research, but could do much to help.

IT is not for nothing that Professor Heinz Staab, the retiring president of the Max-Planck Gesellschaft (MPG), has been ruminating about the future shape of the organization of which he has been the head since 1984 (see Nature 340, 335; 1989). The truth is that MPG has become the prisoner of its own success. The network of MPG institutes offers people opportunities to follow careers in basic research untrammelled by the customary academic responsibilities for teaching, let alone administration. Although the MPG network has been at the cutting-edge of the remarkable resurgence of basic research in West Germany during the past 15 years, it is not surprising that many of its institutes have also silted up with people whose liveliness has proved less durable than their tenure of their jobs. That is a familiar problem, but one that is bound to seem the more alarming in a system in which federal support for basic research is channelled almost equally through MPG institutes on the one hand and through research grants (by the Deutsche Forschungsgemeinschaft) on the other.

Staab's problem will not be solved within the MPG system itself, but only in the broader context of the West German university system. The plain truth is that the university system offers too few opportunities for people in mid-career to become independent scientists with the stature of those called principal investigators in the United States. The need for a means of keeping mid-career people in the university system was recognized, more than a decade ago, by the creation of the system of Heisenberg Fellowships, essentially postdoctoral appointments conceived of as a means by which able researchers could remain in an academic orbit until permanent positions became vacant. The system has been a limited success. Applicants for the fellowships have been of high quality, but the expectations of those appointed have too often been frustrated by the dearth of permanent positions in the university system, which is in turn a measure of the disaffection of Länder governments from further university expansion.

The essential stumbling block is the general assumption in West Germany that only those with permanent positions are able to regard themselves as true academics. The old traditions of the Lehrstühl, in which a newly appointed head of a university department might expect to make a deal on equipment and on his annual budget directly with officials of the Land government, plainly die hard. But MPG, which has substantial funds at its disposal and also a long-term interest in the encouragement of mobility within the research profession, could do a great deal to help, perhaps by the gesture of offering small and nontenured research groups in universities an appropriately informal sense of membership in a larger institute, perhaps on a different site. West Germany is not, after all, so huge and uncommunicative that distance would be a difficulty.

MPG itself would benefit from any arrangement that would allow it more convincingly to reject the complaint that its own talent is too little concerned with the education of the young. In reality, of course, many MPG institutes provide important facilities for the education of graduate students. For instance the radioastronomy institute at Effelsburg, near Bonn, is an almost indispensable means by which graduate students earn degrees in radioastronomy. The mathematics institute, also at Bonn, is both a national centre of excellence and almost a part of the University of Bonn. But there are other institutes whose direct contribution to teaching and training in research should be greater and more direct. And there is something in the opinion that the supervision of graduate students is the lesser part of the process of higher education. MPG could benefit not only West Germany but itself by planning more deliberately to integrate its institutes with universities. 